\title{
DIETARY PRACTICES AND SELF ADHERENCE TO TYPE 2 DIABETIC MANAGEMENT AMONG URBAN POPULATION OF CHENNAI METROPOLITON CITY-A CROSS SECTIONAL STUDY
}

\section{Dr Aravind Raj*}

Dr Sankar A
Junior Resident, Department of General medicine, Sree Balaji Medical college and Hospital, No 7, works road, Chrompet, Chennai, Tamil Nadu, India-600044. *Corresponding Author

Associate Professor, Department of General medicine, Sree Balaji Medical college and Hospital, No 7, works road, Chrompet, Chennai, Tamil Nadu, India-600 044.

\section{ABSTRACT}

Background: The prevalence of Diabetes Mellitus is 2.4\% among adults in rural population and 4-11.6\% in urban population. In recent years, the simultaneous acceleration of diabetes and obesity worldwide has led to increasingly sedentary lifestyles and poor eating habits. Even children exposed to "junk" food and without enough exercise have now experienced obesity and diabetes. The term metabolic syndrome (formerly called 'Syndrome $\mathrm{X}$ ') has been applied to an increasingly common disorder in which abdominal obesity and insulin resistance, such as elevated lipid profiles, are accompanied by a constellation of risk factors for cardiovascular disease.

Objectives: To observe the dietary patterns of diabetic patients of urban Chennai population.

Methods: A cross sectional study was conducted among diabetic patients attending the general out patient department of Balaji medical college hospital Chennai. Patients with following blood glucose levels were taken as Diabetics, $\mathrm{F} \geq 126 \mathrm{mg} / \mathrm{dl}, \mathrm{PP} \geq 200 \mathrm{mg} / \mathrm{dl}$. Individuals diagnosed and treated for the above conditions for one year or more will be treated as participants. Purposive sampling was used to achieve the sample size of 164 participants. After obtaining the informed consent, the patients were enrolled for the study. Data was analysed using SPSS ver.24. Descriptive data was given in frequency and percentage. chi-square test was used to compare the data. p-value $<0.05$ was considered as statistically significant.

Result: Among the diabetic patients, their mean level of fasting sugar was 140 and PP was 236 with SD 44.032 and 62.674 . More than $65 \%$ of the Urban population follow some other diet restrictions such as low salt, low cholesterol and fat. Physical activity of the population are $57 \%$ of going for walking also $39 \%$ of them are had no physical activity at all.

Conclusion: The dietary change coupled with, the intake of cholesterol rich food and lack of physical activity seem to have contributed to the urban population's high prevalence rate of obesity.

\section{KEYWORDS : Diabetes, Diet Pattern, Urban Population}

\section{INTRODUCTION}

About 4.9 million adults a year are killed by diabetes. It is a rising noncommunicable disease, a major threat to global public health, particularly in India. Diabetes mellitus ( DM) is a disorder of carbohydrate, fat, and protein metabolism induced by loss of insulinproducing cells in the pancreas or reduced sensitivity of the tissues to insulin, resulting in elevated blood glucose levels. Combined with urbanisation and industrialization, demographic change has led to dramatic changes in lifestyles worldwide, but due to their higher growth rate, the effect is felt more in developing countries. A shift in disease trends of communicable diseases being substituted by noncommunicable diseases is one of the implications of this transition.(1) In comparison to many communicable diseases, NCDs are one that has the highest propensity to inherit somehow in the life of the offspring and continues its journey, which often requires long, even lifelong treatment and more life style changes to achieve a reasonable quality of life. Diabetes is a condition or disorder rather than a disease, where either there is inadequate pancreatic secretion of insulin or its absorption by cells in the body occurs, leading to increased accumulation of insulin in the body and leads to many complications. Diabetes holds a prime place among numerous non-communicable or life-style diseases such as diabetes mellitus, hypertension, cardiovascular diseases, cancer, asthma and auto immune diseases, etc., as it is itself a risk factor for many other diseases and has a high prevalence rate worldwide. It is now easy to categorise this condition into type 1 and type 2 diabetes mellitus as insulin-dependent (IDDM) and non-insulin - dependent (NIDDM) diabetes since diabetes will need to be later artificial insulin at times in their life time.(2)

The cause of diabetes is multifactorial, such as high calorie diet consumption, lack of physical activity correlates to diet and body weight consumption, inheritance and obesity. In developing and controlling diabetes, diet plays a major role. Regimen adherence problems are common in individuals with diabetes, making glycemic control difficult to attain, but the risk of complications of diabetes can be reduced by proper adherence. The World Health Organization (WHO) defined adherence as "the extent to which a person's behaviour - taking medication, following a diet, and/or executing lifestyle changes, corresponds with agreed recommendations from a health care provider" A diabetic diet should have high-carbohydrate and high- fiber (HCHF),(3) low glycemic index foods, high monounsaturated fatty acids (MUFA) and low saturated fats that are very satisfied by typical Asian cereal-based diets such as foods containing coarse grains of sorghum, barley, rye, maize and millets. Therefore, diabetes treatment requires strict adherence to eating patterns, physical activity, and medications. This study attempted to expose dietary habits and self-adherence to diabetes management in Chennai City's urban population.

\section{METHODS}

A cross sectional study was conducted among diabetic patients attending the general out patient department of Balaji medical college hospital Chennai. Patients with following blood glucose levels were taken as Diabetics, $F \geq 126 \mathrm{mg} / \mathrm{dl}, \mathrm{PP} \geq 200 \mathrm{mg} / \mathrm{dl}$. Individuals diagnosed and treated for the above conditions for one year or more will be treated as participants. Purposive sampling was used to achieve the sample size of 155 participants. After obtaining the informed consent, the patients were enrolled for the study. Data was analysed using SPSS ver.24. Descriptive data was given in frequency and percentage. chi-square test was used to compare the data. p-value < 0.05 was considered as statistically significant.

\section{RESULTS}

A total of 164 diabetic patients were enrolled for this study. The basic demographic details are given in the below table-1. Among the total 41-60 years age group are high in this study followed which more 60 years.Male diabetic patients are more than the female. Around $93 \%$ of them were married.

Table-1: Demographic Characteristics Of The Participants

\begin{tabular}{|c|c|c|c|}
\hline \multicolumn{2}{|l|}{ Variables } & Frequency & $(\%)$ \\
\hline \multirow[t]{3}{*}{ Age } & $21-40$ & 22 & 13.41 \\
\hline & \begin{tabular}{|l|}
$41-60$ \\
\end{tabular} & 108 & 65.85 \\
\hline & $>60$ & 34 & 20.73 \\
\hline \multirow[t]{2}{*}{ Gender } & Male & 101 & 62.68 \\
\hline & Female & 63 & 37.31 \\
\hline \multirow{4}{*}{ Marital status } & Unmarried & 6 & 3.65 \\
\hline & Married & 153 & 93.29 \\
\hline & \begin{tabular}{|l|} 
Divorced \\
\end{tabular} & 0 & 0 \\
\hline & \begin{tabular}{|l|} 
Widow \\
\end{tabular} & 5 & 3.04 \\
\hline
\end{tabular}


Volume - 10 | Issue - 11 | November - 2020 | PRINT ISSN No. 2249 - 555X | DOI : 10.36106/ijar

\begin{tabular}{|l|l|l|l|}
\hline \hline \multirow{5}{*}{ Education } & Illiterate & 9 & 5.48 \\
\cline { 2 - 4 } & High school & 93 & 56.70 \\
\cline { 2 - 4 } & College & 25 & 15.24 \\
\cline { 2 - 4 } & Professionals & 37 & 22.56 \\
\hline \multirow{5}{*}{ Occupation } & Employed & 61 & 37 \\
\cline { 2 - 4 } & Unemployed & 71 & 44 \\
\cline { 2 - 4 } & Others & 32 & 19 \\
\hline & $<5000($ very low) & 1 & 0.6 \\
\cline { 2 - 4 } & $5000-10000($ low $)$ & 22 & 13.41 \\
\cline { 2 - 4 } & $10000-20000($ average) & 74 & 45.12 \\
\cline { 2 - 4 } & $20000-30000($ above average) & 57 & 34.75 \\
\cline { 2 - 4 } & $>30000($ above) & 10 & 6.09 \\
\hline
\end{tabular}

While comparing the adherence level within group population there was a significant difference was observed.

Table-5: Type Of Physical Activity

$56 \%$ of them were completed their high school education compare to other.only $37 \%$ of them were employed and $45 \%$ of them had monthly income of 10000 to 20000 per month.

Table-2: Distribution Of Blood Glucose Level

Mean blood glucose fasting \& postprandial

\begin{tabular}{|l|l|l|l|l|l|}
\hline $\begin{array}{l}\text { Recent blood } \\
\text { glucose level }\end{array}$ & $\mathbf{N}$ & $\begin{array}{l}\text { Minimum } \\
(\mathbf{m g} / \mathbf{d l})\end{array}$ & $\begin{array}{l}\text { Maximum } \\
(\mathbf{m g} / \mathbf{d l})\end{array}$ & $\begin{array}{l}\text { Mean } \\
(\mathbf{m g} / \mathbf{d l})\end{array}$ & $\begin{array}{l}\text { Std. } \\
\text { Deviation }\end{array}$ \\
\hline Fasting & 164 & 82 & 330 & 140.73 & 44.032 \\
\hline Post Prandial & 164 & 116 & 556 & 236.07 & 62.674 \\
\hline
\end{tabular}

Among the diabetic patients, their mean level of fasting sugar was 140 and PP was 236 with SD 44.032 and 62.674.(table-2)

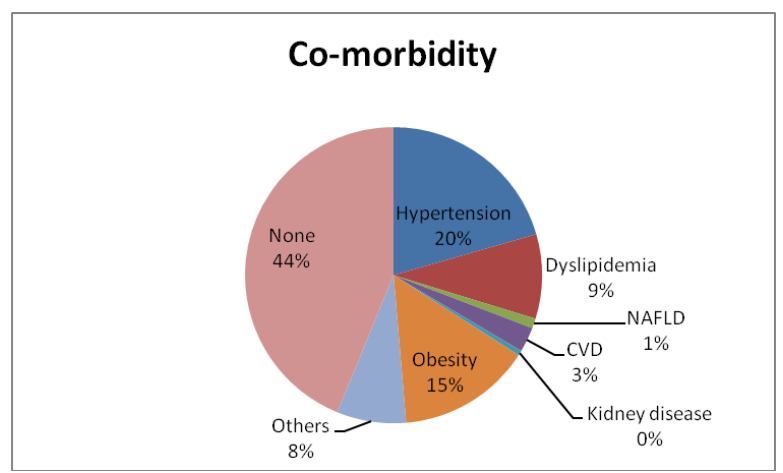

\section{Chart-1: Co-morbid Conditions}

Around $20 \%$ of them developed hypertension and $15 \%$ are obesed and $44 \%$ had no disease.(Chart- 1 )

Table-3: Diet Restriction By Diabetic Patients

\begin{tabular}{|l|l|l|}
\hline Diet restriction & Frequency (N) & $(\mathbf{\%})$ \\
\hline Yes & 106 & 64.63 \\
\hline No & 58 & 35.36 \\
\hline
\end{tabular}

More than $65 \%$ of the Urban population follow some other diet restrictions such as low salt, low cholesterol and fat.(Table-3)

Table-4 Intake Of Direct Sugar

\begin{tabular}{|l|l|l|}
\hline Intake of direct sugar & Frequency & $\%$ \\
\hline Yes & 72 & 43.9 \\
\hline No & 92 & 56.09 \\
\hline
\end{tabular}

Around $43 \%$ of them are consume direct sugar among these study group.

Table-6: Consumption Of Tubers

\begin{tabular}{|l|l|l|}
\hline Consumption of tubers & Frequency & $\mathbf{\%}$ \\
\hline Never & 70 & 42.68 \\
\hline Occasionally & 69 & 42.07 \\
\hline Usually & 23 & 14.02 \\
\hline Always & 2 & 1.21 \\
\hline
\end{tabular}

$42 \%$ of them never take tubers to control the diabetes and only $1 \%$ of always consume tubers.

Table-7. Diet Adherence Level Within Group Comparison

\begin{tabular}{|l|l|l|l|}
\hline Diet adherence level & Frequency & $\%$ & $\begin{array}{l}\text { Within group } \\
\text { comparison }\end{array}$ \\
\hline Non desirable adherence & 40 & 24.39 & 0.009 \\
\hline desirable adherence & 124 & 75.6 & \\
\hline \hline
\end{tabular}

\begin{tabular}{|l|l|l|}
\hline Type of physical activity & Frequency $(\mathbf{N})$ & $(\%)$ \\
\hline Walking & 95 & 57.92 \\
\hline Jogging & 1 & 0.6 \\
\hline Exercises & 1 & 0.6 \\
\hline Yoga & 0 & 0 \\
\hline Walking and yoga & 1 & 0.6 \\
\hline Walking and others & 1 & 0.6 \\
\hline No physical activity & 65 & 39 \\
\hline
\end{tabular}

The above table shows that $57 \%$ of going for walking also $39 \%$ of them are had no physical activity at all.

\section{DISCUSSION}

An increase in diabetes prevalence has been shown by epidemiological evidence from different parts of India. Different results were found in the present study compared to other research, despite the adoption of WHO standards, which may be attributable to discrepancies in blood glucose calculation methodologies, diabetes description, age group and geographical situations. Diabetes treatment is complex and includes strategies for health risk reduction beyond regulation of blood sugar.(4) The difficulty of self-management practises involving diabetes requires lifelong support and education. (5) Dietary carbohydrate restriction has been reported as single most effective intervention in the control and treatment of diabetes. (6) Self-care is considered essential for the treatment of diabetes; self-management remains one of the pillars of the self-care mechanism for diabetes. (7) As such, SMBG (blood glucose self-monitoring), carbohydrate counting, and regimens of activity are important and should be individualised in everyday life for each diabetes patient. (8) In this study male population was $67.68 \%$. In the present study, we assess the association of dietary patterns with the risk of DM . In this study majority of them are under diet control that $65 \%$. But around $39 \%$ of them are not having any physical activity.This research has some possible drawbacks that need to be highlighted. First, since our research is a cross-sectional design research, it is possible to determine no cause-and - effect associations between dietary habits and the risk of DM and central obesity. Second, some arbitrary and subjective judgments should be taken into account in the use of factor analysis. Among the total patients enrolled around $20 \%$ of them are having hyperrtenion,CVD $3 \%, 15 \%$ obesity, $9 \%$ had dyslipidemia and $44 \%$ of them did not have any comorbidity. While comparing the diet adherence level within group there was a significant difference was observed. The study created awareness of diabetes and its complications in this region's population. These findings may be useful for the implementation of the National Diabetes Control Programme.

\section{CONCLUSION}

In order to minimise the incidence, less than half of the diabetic patients maintain their food regulation and physical activity, knowledge should be developed for better adherence to type 2 diabetes treatment in both classes. Intensive dietary modifications should be taken out for individual level by advising traditional cereal based foods with low glycemic index and high mono unsaturated fatty acids depends on the individual's metabolic, caloric needs and BMI and income status. Routine blood sugar, lipid profile and $\mathrm{HbAl} \mathrm{c}$ should be monitored regularly for the effective management and prevention of diabetes complications.

\section{Acknowledgement:}

I thank all the participants for their active participation.

\section{REFERENCES}

1. Gimeno SG, Ferreira SR, Franco LJ, Hirai AT, Matsumura L, Moises RS. Prevalence and 7-year incidence of Type II diabetes mellitus in a Japanese-Brazilian p op u lation: An alarming public health problem. Diabetologia 2002;45:1635-8.

2. Global prevalence of diabetes: estimates for the year 2000 and projections for 2030 Wild S, Roglic G, Green A, Sicree R, King H, Diabetes Care. 2004 May; 27(5):1047-53

Roglic G, Unwin N. Mortality attributable to diabetes: estimates for the year 2010 Roglic G, Unwin N. Mortality attrib

4. Vermeire E, Hearnshaw H, Van Royen P et al. Patient adherence to treatment: Three decades of research. A comprehensive review. J Clin Pharm Ther. 2001;26:331-42.

5. Nagelkerk J, Reick K, Meengs L. Perceived barriers and effective strategies to diabetes self-management.JAdv Nurs.2009; 54:151-8.

6. Feinman RD, Pogozelski WK, Astrup A et al. Dietary carbohydrate restriction as the first approach in diabetes management: Critical review and evidence base .Nut. 2015;31(1):1-13.

7. Tol A, Shojaeezadeh D, Sharifirad GH et al. Predictors of self-management behaviors among type 2 diabetes patients. J Basic Appl Sci Res. 2012;2:2270-4

8. Sigal RJ, Kenny GP, Wasserman DH, Wasserman DH.et al. Physical activity/exercise and type 2 diabetes. Diabetes Care. 2006;29(6):1433-1438. 